Rev. Chil. Podiatr. 62 (2); $128-131,1991$

\title{
Epiglotitis aguda
}

\author{
Patricio Rumero P. ${ }^{1}$; Ricardo Ronco $\mathrm{M}^{2}{ }^{2}$; Patricia Madrid R. ${ }^{3}$
}

\section{Acute epigkotitis}

\begin{abstract}
Acute epiglotitis caused by Hamophilus influenzae type $B$ (Hibl is seldom described in Chile. To reinforce the need to take this severe entity into account in the differential diagnosis of acute upper respiratory tract obstructions, the case of a 9 month oid girl is described. who's symptoms were initially attributed to acute laryngitis, but showed not response to racemic epinephrine and betamethasone therapv. The correct diagnosis of acute epiglotitis was suggested five hours after admission by lateral neck's radiographs and confirmed by direct laryngoscopic examination under general anesthesia. Appropriate treatment was soon instituted including trachea! intubation respiratory support and antibiotics. An uneventful clinical course proceeded trom then on. Hemophilus influenzae $B$ was isolated from blood cultures.

(Key words: Haemophilus influenzae type B, epiglotit is, acute.)
\end{abstract}

La epiglotitis es una celulitis de la epiglotis y de sus estructuras de soporte, de evolución rápidamente progresiva en la mayoría de los casos. Afecta a niños entre 3 y 6 años, aunque también puede comprometer a lactantes; es provocada habitualmente por Haemophilus influenzae tipo B (Hib), y esporádicamente por Staphilococcus aureus, Streptococtus grupo A y Streptococcus neumoniae. En Chile la localización epiglótica de las infecciones por $\mathrm{Hib}$ es poco frecuente. En nuestro hospital, a lo largo de 4 años (desde 1986 a 1989), de un total de 69 hemocultivos positivos a dicho germen no se registró ningun caso de localización epiglótica; en series extranjeras su frecuencia varía entre 1,5 y $23 \%$ del total de infecciones por $\mathrm{Hib}^{2}$.

En consideración a la gravedad evolutiva de esta enfermedad y la importaricia que tienen su diagnóstico precoz y el manejo oportuno y eficiente de la emergencia, describiremos el caso de un lactante con epiglotitis, comentando, además, el diagnóstico diferencial en un niño que presenta, bruscamente, dificultad respiratoria altal.

1. UCl. Hospital Kxequiel González Cortés.

2. Hospital Fxequiel González Cortés. Pediatría.

3. UCI. Hospital Exequiel González Cortés.

\section{Caso Clínico}

Niña de un ảo 9 meses, șin antecedentes mórbidos ni perinatales de importancia, que 14 horas antes del ingreso sufrió, en forma brusca, fiebre con temperatura de $40^{\circ} \mathrm{C}$, disfonia leve, rechazo de los alimentos y decajmiente, agregándosele, dos horas antes del ingreso, dificultad respiratoria severa de instalación brusca, con cianosis perioral, motivo por el cual consultó en la unidad de urgencia, hospitalizándose con las hipótesis de laringitis obstructiva y cuerpo extraño en la vía ačrea.

Se inició tratamiento con $\mathrm{O}_{2}$ en hălo, ncbulizaciones de epinefrina racémica, betametasona y soluciones glucosalinas endovenosas, en coincidencia con to cual se obscrvó leve disminución de sus síntomas. Sin embargo, 5 horas despues de ingresar estaba sin fiebre, su trecuencia cardíaca era $120 \cdot \mathrm{min}$, frecuencia respiratoria 45 - min, decaída, de aspecto grave, con hiperextensión marcada del cuello y tiraje, después de una nueva nebulización con epinefirina racémica sin zesultados clínicos positivos. La radiografía portátil lateral del cuello (figura 1) reveló importante aumento de volumen de la epiglotitis, interrupción parcjal del paso de la columna de aire y dilatación del espacio faríngeo. Bajo anestesia general se realizó laringoscopía directa, obscrúndose epiglotis enrojecida, brillante y aumentada de volumen, procediéndose a irtubación nasotraqueal, apreciándose rápida desapatición de la dificultad respiratoria. Por su condición de agotamiento y gravedad, se conectó a ventilación mecánica, se tomaron hemocultivas $y$ se injeió tratamiento parenteral con ampicilina $y$ cloranfenicol, luego de lo cual evolucionó sin fiebre $y$ con buena tolerancia a la ventilación mecánica. Los exámenes de ingreso mestraron aumento de tos glóbulos blancos a 15.200 por $\mathrm{mm}^{3}, 13 \%$ baciliformes $y$ $59 \%$ de segmentados en el hemograma. Velocidad de sedimentación de los eritrocitos (VHS) $50 \mathrm{~mm}$ en la 


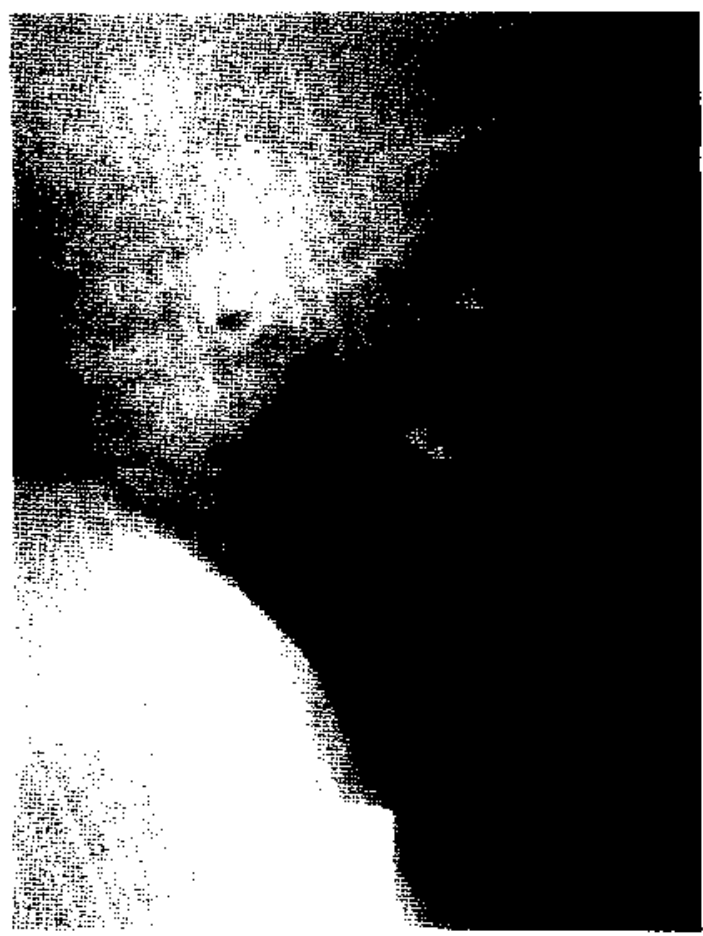

Figura 1: Radiografía tateral del cuello al ingreso. Se observa importante aumento de volumen de la epiglotis (signo pulgar) con dilátación del especio faringoesofásica e interrupción parcial de la columna de aire.

prìmera hora. En la sangre arterial el pH era 7,37, $\mathrm{PCO}_{2}$ $36 \mathrm{~m} \mathrm{Hg}$ y $\mathrm{PO}, 75 \mathrm{~min} \mathrm{Hg}$. La radiogratía de tórax fue normal. Los hemocultivos dieron resultado positjuo para Hib no productor de betalactamasa. por lo que 72 Il después de iniciar el tratamiento se suspendió el cloranfenicol, previa laringoscopia y radiografía lateral de cuello que mostraba desaparición de los signos inflamatorios epiglóticos, fue posible extubarla, evolucionando sin difjeultad respiratoria $y$ en buenas condi- ciones generales: se dio de alta 7 dias después de ingresar, con tratamiento antibiótico oral, hasta completar 10 dias.

\section{Discusión}

Se ha señalado que $25 \%$ de las epiglotitis ocurren en menores de 2 años ${ }^{2,3}$. Esta información es importante, ya que corresponde al periodo en que es más común diagnosticar laringitis obstructivas virales. La epiglotitis ocurre preferentemente en niños entre 3 y 6 años, sin infección viral previa, se inicia bruscamente con fiebre alta, dificultad respiratoria progresiva, aspecto de intoxicación, posición de "olfateo", sialorrea y cianosis. Las manifestaciones clínicas pueden variar, especinlmente en lactantes, lo que induce a error diagnóstico y tardanza en el manejo oportuno ${ }^{3,5-7}$.

El diagnóstico diferencial debe realizarse con cualquier disfagia febril en lactactes y preescolares con dificultad respiratoria aguda 5,6 . En la tabla 1 se ofrece una lista de problemas obstructivos de la vía aérea superior, clasificadas de acuerdo a la ubicación topográfica de las lesiones y su etiología.

Las complicaciones más temidas de las epiglo. titis son la obstrucción respiratoria completa y el paro cardíaco, que puede ocurrir inesperadamente 0 desencadenarse por hacer examen de la faringe o procedimientos radiológicos sin tomar las debidas precauciones; se recomienda, por lo tanto, evitar toda situación que angustie al nin̄o y, si la maniobra se estima inevitable, contar con un médico preparado para intubar do inmediato, si las circunstancias to requieren.

A pesar de lo controvertido del uso de la radiografía lateral de cuello ${ }^{8,}{ }^{9}$, parece evidente

Tabja 1

Síndrome supraglóticos

Infecciones de tejidos blandos:

Absceso retrofaringeo

Absceso periamigdaliano

Celulitis de la taringe

Fpiglotitis

Causas no infecciosas:

Cuerpo extraño o lar íngeo

Traumatismo

Cáncer

Edema angioneurótico de la glotis
Laringitis obstructiva viral Laringotraqueitis bacteriana Difteria

Cuerpo extraio

Malformación congénita

Masa extrínseca

Croup espasmúdico recurrente 
su utilidad en los casos sospechosos y con adecuadas medidas de precaución. Una vez confir. mado el diagnóstico, el nianejo debe ser realizado en una unidad de cuidado intensivo pediátrica, instalación vía aérea permeable mediante intubación nasotraqueal en pabellón quirúrgico, con apoyo de anestesista y otorrinolaringólogo. El nıanejo posterior incluye oxigenoterapia, humidificación del aire inspirado, aspiración cuidadosa de las secreciones y mantención del equilibrio hidroelectrolitico, procurando evitar sobrecargas que podrian agravar la posible, aunque infrecuente, asociación con edema pulmonar, condición clínica que se observa en la evolución de niños intubados por obstrucción respiratoria grave. Además es preciso inmovilizar y sedar al paciente intubado, con morfina 0,1 $\mathrm{mg} \cdot \mathrm{kg}$ por vía endovenosa o intramuscular cada 4 horas o bien con diazepán $0,3 \mathrm{mg} \cdot \mathrm{kg}$ endovenoso. El tratamiento con antibióticos deberá cubrir Hib y luego se correlacionará con la sensibilidad demostrada siendo recomendable su administración por vía endovenosa hasia la extubación, para continuarlo posteriormente por vía oral, hasta completar 10 dias.

El apoyo ventilatorio fue, en este caso, de gran utilidad en la fase inicial. La extubación procede generalmente entre 24 y 96 horas después de instalado, previa confirmación clínica, radiológica y laringoscópica de regresión de la inflama. ción (figura 2).

La asociación de epiglotitis con otros focos infecciosos es rara, pero siempre deben investigarse meningitis, neumonía, pericarditis o artritis $^{3,4}$. El pronóstico final estará determinado por la precocidad del diagnóstico y el inicio adecuado y oportuno del tratamiento.

\section{Resumen}

Se describe el caso de un lactante con epiglo. titis (E) por Haemophitus influenzae tipo B (Hib), cuyas manifestaciones fueron las de un sindrome de dificultad respiratoria alta, progresivo, que no respondió al tratamiento con epinefrina racémica y betametasona. La radiografia portátil lateral del cuello reveló aumento de volumen de la epiglotitis, interrupción parcial del paso de la columna de aire y dilatación del espacio faríngeo. En los hemocultivos se identificó Hib. La paciente fue tratada con intubación traqueal, ventilación asistida, ampicilina y clo.

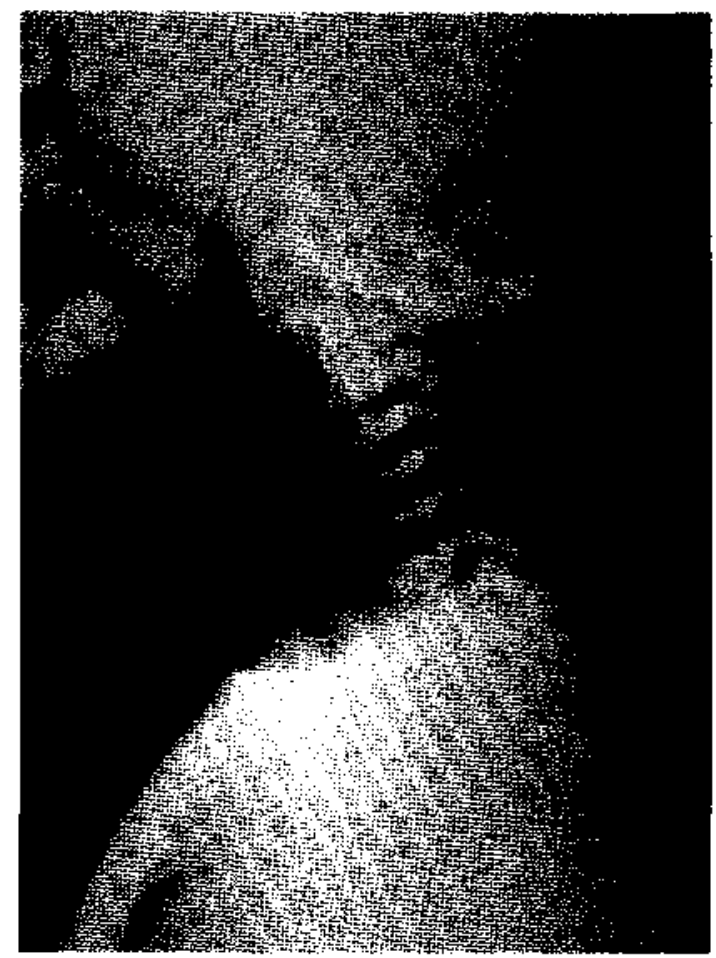

Figura 2: Radiografía lateral del cuello, 72 horas después de iniciar el tratamiento. Se puede observar desaparición de los signos inflamatorios en el momento de extubar a los pacientes.

ranfenicol y evolucionó satisfactoriamente. A pesar de la poca frecuencia con que se describe esta enfermedad en Chile, es necesario tenerla presente en el diagnóstico diferencial de las obstrucciones respiratorias altas por la severidad de su evolución y las caracteristicas especificas de su tratamiento.

(Palabras clave: epiglotitis, obstrucción respiratoria alta, Haemophilus infuenzae tipo B.)

\section{Referencias}

1. Marcus, M,; Semel, L.: An unusual case of epiglotitis in a patient witl asthma. Pediatr Emerg Care 1988; $4: 124-126$.

2. Nesheim, S.: Wilcox, D.: Systemic Hemophilus influenzae disease in childre. Clin Ped 1986:25: 605-609.

3. Brilli, R.: Bensing, G.; Cotcamp, D.: Epielotitis in infants less than two years of age. Pediatr Energ Care 1989, 5: 16-20.

4. Daum, R.S.; Smith, Al:: Epiglotis en: Textbook of Pediatric Infections Disease. Philadelphia, W.B. Saunders 1987;224-237. 
5. Kilham, H.; Gillis, J.: Benjamin, B.: Severe upper airway obstruction. Pediatr Clin North Am 1987; $34: 13$.

6. Botoglia, J.D.; Lockhart, Ch.: Management of acute epiglotitis by nasotracheal intubation. Am J. Dis Child $1975 ; 129: 334.336$.
7. Foden, H.S.: Treatment of Hemophilus inlluenzae type B epiglotitis. Pediatrics $1979 ; 63 ; 402-407$.

8. Margolis, L.: Are lateral neck X-rays a waste o1 time? Pediatrics 1981;63:469.

9. Baster, F: Upper and lower airway emergencies: Pediatrics Advance Life Support. Jarvis-Greenway 1987: $100-143$. 